\title{
Modifikasi Alat Pelindung Kaki dalam Mencegah Timbulnya Ulkus Kaki pada Penderita Diabetes Melitus
}

\author{
Hartanto \\ Staf Pengajar Bagian Anatomi, Fakultas kedokteran, Universitas Kristen Krida Wacana \\ Alamat Korespondensi : hartanto.hartono@yahoo.com
}

\begin{abstract}
Abstrak
Kaki tersusun atas tulang, otot, sendi, ligamentum, sistem limfe dan sistem neurovaskular yang sangat penting dalam mendukung aktivitas dalam kehidupan manusia. Kaki terdapat di distal tubuh dan memiliki struktur rangka khusus, sehingga pada saat menjalankan fungsinya akan terpapar terhadap lingkungan. Hal ini menyebabkan kaki rentan mengalami trauma, baik dari lingkungan maupun dari dalam tubuh. Ulkus plantar merupakan salah satu komplikasi kronis pada kaki penderita diabetes melitus yang tidak ditangani dengan baik. Terapi medikamentosa masih merupakan pilihan utama pada ulkus plantar, namun tindakan pencegahan merupakan salah satu faktor penting dalam mendukung pemulihan dan pencegahan kejadian ulkus plantar. Pemanfaatan alat pelindung kaki merupakan salah satu bagian dari tindakan pencegahan yang penting. Kaki penderita diabetes melitus mengalami perubahan struktur makro maupun mikro sehingga tidak dapat menggunakan alat pelindung kaki biasa seperti yang digunakan oleh orang sehat. Oleh karena itu, perlu dilakukan modifikasi pada bagian-bagian alat pelindung kaki yang sesuai dengan kebutuhan penderita. Penggunaan modifikasi alat pelindung kaki merupakan salah satu tindak pencegahan yang telah terbukti dapat mengurangi tekanan plantar pada area spesifik di kaki, sehingga kejadian luka baru atau perburukan luka dapat dicegah.
\end{abstract}

Kata kunci : ulkus plantar, modifikasi alat pelindung kaki, tekanan plantar

\section{Footwear Modification in Preventing Plantar Ulcer in Diabetes Melitus Patients}

\begin{abstract}
The foot is composed of bones, muscles, joints, ligaments, lymphatic system and neurovascular system which are very important in supporting activities in human life. The foot is distal of the body and has a special skeletal structure, so that when carrying out its functions, it will be exposed to the environment. This causes the foot to be prone to trauma, both from the environment and from the body. Plantar ulcer is a chronic complication in the feet of patients with diabetes mellitus who are not treated properly. Medical therapy is still the main choice for plantar ulcers, but preventive measures is an important factor in supporting the recovery and prevention of plantar ulcers. The use of footwear is an important precaution. The diabetic foot undergoes changes in macro or microstructure, so they cannot use ordinary footwear used by healthy people. It is necessary to modify the parts of footwear that suit the patient's need. The use of modification footwear is a preventive measure that has been proven to reduce plantar pressure in specific areas of the foot, so that the incidence of new injuries or worsening of injuries can be prevented.
\end{abstract}

Keywords : plantar ulcers, footwear modification, plantar pressure 


\section{Pendahuluan}

Diabetes melitus merupakan penyakit kronik yang telah berdampak kepada hampir 200 juta orang di dunia dan diprediksikan akan meningkat $25 \%$ pada dekade berikutnya. ${ }^{1}$ Negara Amerika mencatat bahwa penyakit diabetes melitus merupakan penyakit yang membutuhkan perawatan kesehatan yang mahal, baik untuk mendanai kecacatan, biaya pekerjaan, dan kematian prematur. ${ }^{1}$ International Diabetes Federation (IDF) menemukan 8,5 juta penduduk negara Indonesia menderita diabetes melitus pada kisaran umur 20 sampai 79 tahun di tahun 2013. ${ }^{2}$ Angka ini diprediksikan akan semakin meningkat menjadi 14,1 juta penduduk pada kisaran umur yang sama di tahun 2035 . $^{2}$

Center of Disease Control and Prevention (CDC) tahun 2004 mencatat sebesar 60 - 70\% penderita diabetes melitus mengalami neuropati perifer, dengan gejala hilang atau berkurangnya sensasi sensorik ekstrimitas distal sehingga mencetuskan timbulnya ulkus plantar. $^{3}$ Penderita diabetes melitus dengan ulkus plantar dapat mengalami komplikasi berupa infeksi dalam di kaki, sepsis, hingga amputasi ekstrim pada tungkai bawah. ${ }^{3}$ Munculnya ulkus plantar pada penderita diabetes melitus disebabkan oleh banyak faktor, mulai dari terjadinya gangguan penyediaan pembuluh darah, adanya luka sebelumnya pada kaki, perawatan kaki yang tidak baik, jeleknya kontrol metabolik, hingga kepada penggunaan pelindung kaki yang tidak sesuai. $^{3}$

Beberapa literatur medis di bidang neuropati kaki menekankan pentingnya penggunaan alat pelindung kaki yang baik sebagai tindakan preventif dan kuratif dari ulkus plantar pada penderita diabetes melitus. ${ }^{4}$ Penelitian alat pelindung kaki dan sendi (pedothric) terus dikembangkan dalam upaya untuk menurunkan tingginya tekanan plantar bagi para penderita diabetes melitus, yakni dengan mengurangi puncak tekanan plantar sehingga dapat disediakan sepatu khusus sebagai alat yang efektif dalam mencegah timbulnya ulkus kaki bagi penderita diabetes melitus. ${ }^{1,4}$

Penelusuran pustaka terhadap struktur kaki, ulkus kaki diabetik, alat pelindung kaki dan modifikasinya perlu diungkapkan sehingga dapat memahami pentingnya modifikasi alat pelindung kaki sebagai tindakan preventif dan kuratif untuk menangani ulkus plantar pada penderita diabetes melitus.

\section{Struktur Tulang, Otot dan Persendian Kaki}

Kaki memiliki struktur kerangka tulang kaki yang tersusun dari 26 tulang kaki yang saling bersambungan melalui persendiannya dan membentuk rangkaian lengkung kaki. ${ }^{5,6}$ Kaki memiliki dua sisi permukaan, yaitu pemukaan kaki yang kontak dengan permukaan tanah disebut plantar dan permukaan atas kaki disebut dorsal. ${ }^{5,6}$ Kaki dapat dipisahkan menjadi tiga bagian, yakni: hindfoot (kaki bagian belakang), midfoot (kaki bagian tengah) dan forefoot (kaki bagian depan). Bagian hindfoot dirangkai oleh tulang tarsal yakni tulang talus (tulang pergelangan kaki) dan calcaneus (tulang tumit) yang akan bersambungan dengan bagian distal tulang tibia dan fibula tungkai bawah untuk membentuk persendian talocrural sehingga kaki mampu melakukan gerak dorsofleksi dan plantar fleksi pada saat berjalan. ${ }^{7}$ Tulang calcaneus dan talus juga membentuk persendian subtalar yang berperan untuk mendistribusikan beban yang berasal dari tubuh ke permukaan tanah pada saat bejalan. ${ }^{7}$ Bagian midfoot dirangkai oleh tulang cuboid, naviculare dan cuneiform bagian medial, intermedia, dan lateral yang akan terhubung dengan bagian hindfoot dan forefoot melalui otot-otot dan fasia plantar. $^{7}$ Bagian midfoot berfungsi sebagai shock absorber (peredam kejut) dari beban yang berasal dari batang badan. Bagian forefoot terdiri dari tulang metatarsal dan tulang phalanges. ${ }^{7}$ Tulang metatarsal berjumlah lima buah yang terhubung dengan rangkaian tulang dibagian midfoot melalui sendi talometatarsal. ${ }^{7}$ Tulang phalanges merupakan tulang yang membentuk jari-jari kaki. ${ }^{7}$ Tulang phalanges di setiap jarijari kaki, saling berhubungan melalui sendi interphalanges dan bagian proksimalnya mengadakan persendian metatarsophalangeal dengan tulang metatarsal. ${ }^{7}$ Ketiga bagian kaki yang saling terhubung ini membentuk rangkaian mekanik untuk menyediakan keseimbangan dan mobilitas kaki (Gambar 1). ${ }^{8}$ 


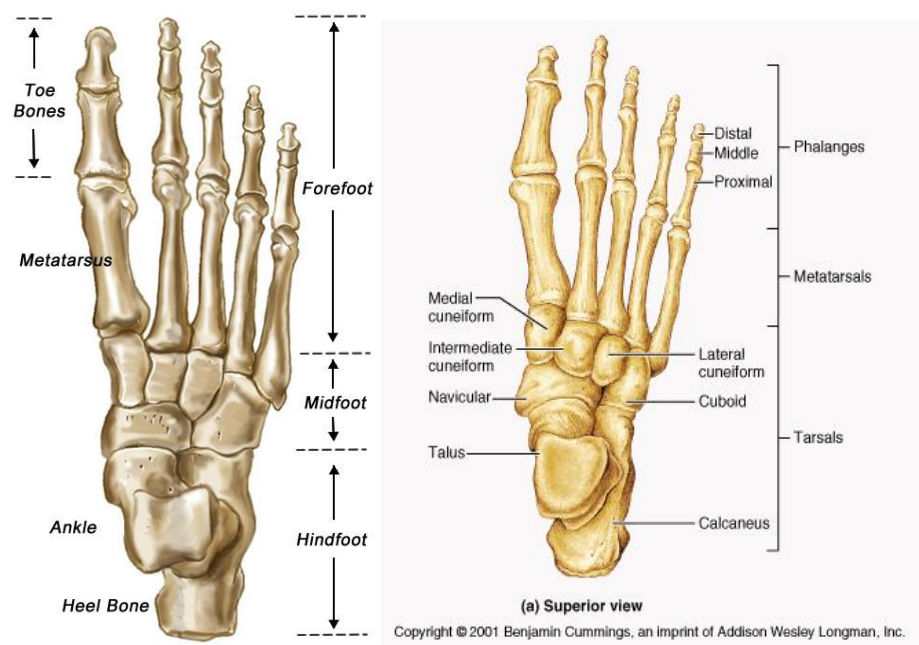

\section{Gambar 1. Bagian-Bagian dari Tulang Kaki dan Tulang Penyusun Kerangka Kaki ${ }^{9}$}

Kaki juga memiliki tiga lengkung, yakni dua lengkung berjalan longitudinal dan satu lengkung berjalan transversal disepanjang kaki yang dibentuk oleh rangkaian tulang tarsal dan metatarsal. ${ }^{10.11}$ Ketiga lengkung ini membentuk sistem peredam kejut (shock absorbing) yang elastis dan berperan untuk mendistribusikan beban tubuh secara merata pada kaki, yakni: separuh berat badan dibebankan ke rangkaian tulang tarsal dan separuhnya lagi dibebankan ke tulang metatarsal. ${ }^{10.11}$ Sepertiga dari berat badan yang dibebankan ke tulang metatarsal, berada pada tulang metatarsal pertama dan sisanya dibebankan pada caput metatarsal lainnya. ${ }^{10.11}$ Melalui lengkung kaki ini beban yang dihasilkan dari berat badan pada saat duduk, berdiri, berjalan atau berlari akan didistribusikan ke tungkai bawah dan berakhir pada kaki sehingga daya yang dihasilkan akibat beban berat badan dan gerakan badan, dapat diredam. ${ }^{10.11}$

Kaki memiliki kelompok jaringan otot yang membantu tungkai untuk bergerak dan mempertahankan keseimbangan kaki, yakni kelompok otot bagian dorsum pedis yang berfungsi untuk melakukan gerakan dorsofleksi kaki dan bagian plantar pedis yang berfungsi untuk melakukan gerakan plantar fleksi. ${ }^{\mathbf{8}, 10}$ Selain struktur kerangka, lengkung kaki dan otot kaki, terdapat sistem pembuluh darah, sistem saraf dan kelenjar getah yang berperan penting untuk memenuhi kebutuhan metabolisme semua sel di daerah kaki. $^{7}$ Sistem pembuluh darah dan sistem saraf tubuh memerlukan jarak tempuh yang jauh agar dapat mencapai kaki yang berada di bagian distal tubuh. ${ }^{7}$ Hal ini menyebabkan kaki menjadi bagian tubuh yang rentan terjadi kerusakan apabila sistem pembuluh darah dan sistem saraf mengalami gangguan, seperti pada penyakit diabetes melitus.

\section{Ulkus Kaki pada Penderita Diabetes Melitus}

Diabetes melitus adalah sindroma klinis kelainan metabolik yang ditandai oleh adanya hiperglikemia akibat gangguan pada sekresi insulin, kerja insulin ataupun keduannya. ${ }^{12}$ Penderita diabetes melitus yang tidak diterapi dengan baik, dapat mengalami komplikasi kronis berupa ulkus kaki. ${ }^{12}$ Ulkus kaki adalah luka pada jaringan kulit kaki yang ditandai dengan terjadinya disintegrasi lapisan-lapisan pada jaringan kulit, baik pada lapisan epidermis, dermis atau sampai kepada lapisan lemak kulit, sehingga terbentuk celah yang memiliki tepi, dinding, dasar dan isi. ${ }^{13}$ Komplikasi kronis ini terjadi akibat adanya gangguan ditingkat pembuluh darah kecil (mikrovaskular), pembuluh darah besar (makrovaskuler) hingga kepada tingkat sistem saraf, baik saraf otonom ataupun perifer. ${ }^{13}$ Gangguan pada mikrovaskuler pada penderita diabetes melitus dapat mengurangi perfusi $\mathrm{O}_{2}$ ke jaringan kaki, sehingga kaki mudah mengalami luka. ${ }^{13}$ Gangguan pada sistem saraf menyebabkan berkurangnya sensasi nyeri pada luka di kaki, sehingga penderita tidak menyadari kemunculan luka tersebut atau tidak memperdulikan luka yang terlihat karena tidak mengganggu aktivitasnya. ${ }^{13}$ Keadaan ini dapat mencetuskan luka kulit semakin memburuk dan menjadi ulkus kaki. ${ }^{13}$ Apabila ulkus kaki tidak diterapi, maka dapat berakhir 
kepada infeksi berulang hingga kepada amputasi jari kaki atau bahkan kaki. ${ }^{13}$

\section{Patofisiologi}

Kondisi hiperglikemia persisten pada penderita diabetes melitus akan mengalami peningkatan aktivitas jalur poliol, sintesis advance glycosilation end products (AGEs), pembentukan radikal bebas dan aktivasi protein kinase C (PKC). ${ }^{13,14}$ Aktivasi berbagai jalur ini akan mengakibatkan rusaknya endotel pembuluh darah, berkurangnya mekanisme vasodilatasi, peningkatan agregasi trombosit dan peningkatan resistensi perifer pada mikro vaskularisasi sehingga berujung kepada gangguan neurovaskuler. ${ }^{13,14}$ Gangguan neurovaskuler jangka panjang akan mengakibatkan neuropati diabetik. ${ }^{13,14}$ Neuropati dan gangguan mikrovaskuler yang berdampak pada kaki akan memberikan tanda klinis yang khas yakni kaki diabetik. ${ }^{13,14}$

Pada kaki diabetik, neuropati yang terjadi akan mengakibatkan sel-sel pada jaringan perifer mudah mengalami iskemia, sehingga trauma ringan dan berkepanjangan dapat dengan mudah menimbulkan ulkus. ${ }^{15}$ Neuropati juga mengakibatkan kerusakan pada saraf morotik yang akan menimbulkan kerusakan pada persarafan otot intrinsik kaki, sehingga terjadi ketidak seimbangan peranan otot-otot fleksor dan ekstensor. ${ }^{15}$ Keadaan ini akan menghasikan kecacatan pada anatomi kaki berupa pembentukan penonjolan tulang abnormal sehingga terjadi peningkatan titik tekan yang secara bertahap di daerah kaki yang menonjol tersebut dan berakhir dengan munculnya kerusakan kulit hingga kepada ulkus. ${ }^{15}$ Neuropati pada saraf otonom akan mengakibatkan penurunan fungsi kelenjar minyak dan kelenjar keringat sehingga kaki kehilangan kemampuan alamiahnya untuk melembabkan kulit. Kulit akan menjadi kering dan terjadi peningkatan kerentangan terhadap regangan dipermukaan kaki, sehingga dapat dengan mudah terjadi ulkus. ${ }^{15}$ Keberadaan ulkus-ulkus ini tidak disadari oleh pasien, karena terjadi penurunan ambang nyeri pada daerah kaki sebagai akibat dari adanya neuropati pada saraf sensoris di kaki. ${ }^{15} \mathrm{Hal}$ ini menyebabkan ulkus yang telah terbentuk akan terus mengalami trauma yang berkepanjangan sehingga ulkus semakin meluas, memburuk atau berakhir dengan amputasi bagian-bagian kaki. $^{15}$

\section{Faktor yang Memengaruhi}

Terdapat beberapa faktor yang ikut berkontribusi dalam mencetuskan terbentuknya ulkus pada kaki diabetik, antara lain: ${ }^{16}$

1. Obesitas dan sindrom metabolik, mengakibatkan peningkatan berat badan yang berlebihan, sehingga beban stress yang akan dialami kaki pada saat berjalan akan meningkat. Hal ini akan mencetuskan kemunculan luka baru pada daerah kaki yang mengalami beban stres.

2. Kondisi hiperglikemia kronis yang akan mengakibatkan angiopati, neuropati, glikosilasi dan gangguan fungsi leukosit, sehingga dapat menghambat proses penyembuhan ulkus.

3. Kondisi malnutrisi dapat menyebabkan hipoproteinemia sehingga menimbulkan edema dan menghambat penyembuhan luka.

4. Immobilitas, mengakibatkan terbentuknya luka akibat tekanan kronis. Pada kondisi ini, biasanya berhubungan dengan malnutrisi, stroke, koma, neuropati, penyakit arteri perifer, inkontinensia dan kontraktur.

5. Faktor lain seperti bertambahnya umur pasien, menurunnya fungsi kognitif, berkurangnya penglihatan, ketidak patuhan terapi, rendahnya respon imun, gangguan sirkulasi dan atrofi kulit, juga memiliki kontribusi dalam mencetuskan ulkus pada kaki diabetik.

Selain faktor pencetus ulkus kaki diabetik, terdapat beberapa faktor risiko yang dapat memperburuk kondisi ulkus pada kaki diabetik, antara lain: ${ }^{16}$

1. Deformitas kaki

Kecacatan pada bentuk anatomi kaki dapat meningkatkan konsentrasi stress yang berulang pada ulkus kaki diabetik. Keadaan ini ditandai dengan adanya eritema pada penonjolan tulang, attenuasi kulit, ulserasi superficial, ulserasi dalam, hingga terjadi infeksi pada lokasi ulkus kaki diabetik.

2. Penyakit arteri perifer

Penyakit arteri perifer dapat mengakibatkan oksigen yang diperlukan untuk proses penyembuhan ulkus dan melawan infeksi menjadi berkurang. 
3. Riwayat ulkus sebelumnya

Adanya riwayat ulkus kaki sebelumnya merupakan faktor resiko signifikan pada luka yang terjadi secara spontan. Adanya ulkus yang pernah muncul pada daerah kaki ini dapat menyebabkan kemunculan ulkus kaki yang baru.

4. Riwayat amputasi

Adanya riwayat amputasi sebelumnya, menandakan kerusakan pada jaringan perifer yang semakin memburuk. Hal ini memberikan indikasi akan terjadinya amputasi kembali pada organ yang lebih proksimal. Amputasi dapat berupa amputasi minor pada jari-jari kaki hingga mayor pada ektrimitas tungkai bawah. Kejadian amputasi area dibawah lutut pada satu kaki, menandakan kecenderungan $50 \%$ untuk dilakukan amputasi pada kaki sebelahnya dalam jangka waktu 5 tahun.

5. Neuropati

Neuropati yang ditandai dengan hilangnya sensasi pada kaki pasien akan menyebabkan keterlambatan diagnosis serta terapinya. Keadaan ini akan mengakibatkan peningkatan tekanan berulang di kaki, hilangnya keseimbangan otot, kekeringan kulit dan atrofi jaringan lunak, sehingga ulkus akan semakin memburuk dan dapat berakhir dengan kecacatan kaki.

\section{Alat Pelindung Kaki dan Peranannya}

Pelindung kaki adalah alat yang digunakan manusia untuk melindungi kaki dari lingkungan. Pelindung kaki juga dapat dimanfaatkan untuk memberikan nilai estetika, memfasilitasi kegiatan tertentu ataupun mendukung kaki yang cacat. ${ }^{17}$
Banyak negara-negara yang telah mengklasifikasikan bagian-bagian dari pelindung kaki. Secara garis besar pelindung kaki memiliki bagian, yakni: upper (bagian atas) dan outer sole (bagian alas kaki). ${ }^{18}$ Kedua bagian ini memiliki dua permukaan, yakni permukaan yang kontak dengan lingkungan luar dan permukaan yang kontak dengan kulit kaki. ${ }^{18}$ Upper merupakan bagian dari pelindung kaki di atas dari alas kaki, namun tidak termasuk lidah (tongue) dan bantalan pada sekitar leher sepatu (collar). Outer sole merupakan bagian yang bila digunakan, akan mengadakan kontak dengan permukaan tanah. ${ }^{18}$ Outer sole biasanya terbuat dari bahan karet, plastik, kulit, kulit buatan, atau kayu yang bila dikombinasikan akan sangat efektif untuk mengurangi tekanan plantar. ${ }^{18}$

Bagian pelindung kaki yang berfungsi untuk mendukung pelindung kaki (reinforcements) (Gambar 2) yaitu: ${ }^{18}$

1. Collar, merupakan bagian tepian dari upper

2. Eyelet, lubang yang berfungsi untuk masuknya tali sepatu, perekat, dll

3. Eye stay, area tempat eyelet berada

4. Foxing, palisan tipis yang berada pada tepi depan palindung kaki

5. Heel counter, bantalan di area tumit dari upper, yang juga menopang upper

6. Heel tab, bantalan di area tumit dari upper dibawah collar

7. Toe cap, bantalan yang digunakan untuk menopang sisi luar dari jari-jari kaki

8. Tongue, penutup untuk melindungi punggung kaki yang dilekatkan pada vamp

9. Vamp, bagian upper yang terletak diantara toe cap dengan eye stay. Memiliki peran untuk melindungi punggung kaki.

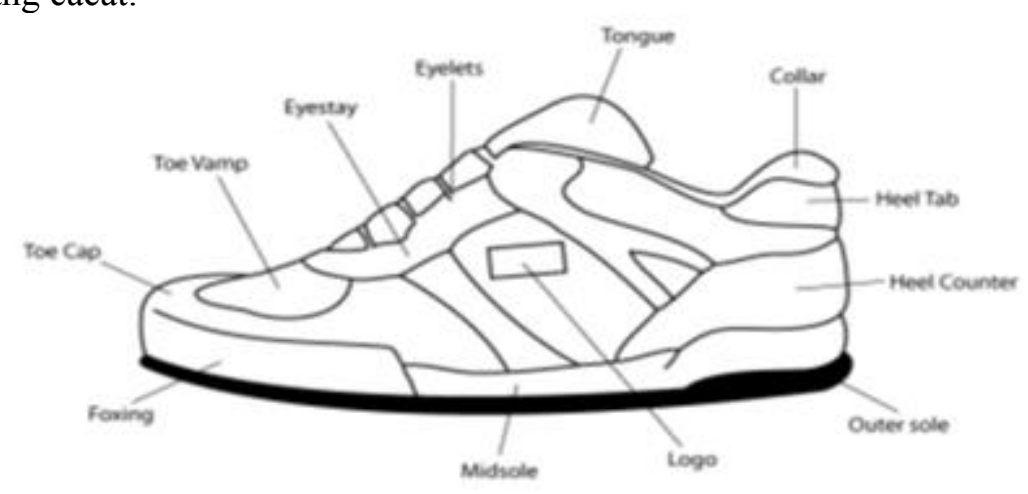

Gambar 2. Bagian-Bagian dari Alat Pelindung Kaki ${ }^{18}$ 
Bagian-bagian dari pelindung kaki ini tidak harus selalu ada pada setiap pelindung kaki. ${ }^{19}$ Setiap bagian pelindung kaki dapat dilakukan modifikasi sesuai dengan kebutuhan penggunanya. ${ }^{19}$ Sebagai contoh bila kaki memerlukan aktifitas yang berat seperti berlari, maka diperlukan sepatu dengan tipe olah raga yang memiliki upper tebal agar bisa memfiksasi persendian di kaki, memiliki outer sole yang tebal sehingga dihasikan shock absorbing yang besar dan biasanya menutupi kaki hingga pada pergelangan kaki. ${ }^{19}$ Modifikasi tipe olah raga ini dapat membuat sepatu lebih protektif namun menjadi lebih berat. ${ }^{19}$ Apabila kaki hanya memerlukan aktivitas ringan seperti berjalan santai dengan jarak pendek, seperti di dalam rumah atau mall, maka sepatu tipe olah raga tidak cocok untuk melindungi kaki, karena bobot sepatu yang berat mengakibatkan dibutuhkan daya lebih besar untuk mengangkat tungkai bawah. ${ }^{19}$ Hal ini akan mengakibatkan tungkai bawah menjadi mudah kelelahan. ${ }^{19}$ Pada aktifitas ringan biasanya digunakan pelindung kaki tipe sandal yang memiliki Upper dan alas kaki yang minimal, sehingga kaki dapat lebih rileks dan tidak mudah mengalami kelelahan, namun kaki terpapar oleh lingkungan. ${ }^{19}$ Penggunaan pelindung kaki yang tidak disesuaikan dengan jenis akitifitas kaki kita dapat mengakibatkan kelelahan, cidera atau bahkan terbentuknya luka pada kaki. ${ }^{19}$

\section{Modifikasi Alat Pelindung Kaki dan Peranannya}

Seiring dengan kemajuan teknologi saat ini, pelindung kaki memiliki bagian-bagian yang saling berkombinasi, seperti: tipe sandal karet yang memiliki outer sole yang tebal namun ringan karena berbahan karet, tipe sepatu olah raga berbahan kain yang ringan namun dapat memfiksasi kaki dengan baik..$^{6,19}$ Hal ini terjadi karena manusia memerlukan pelindung kaki yang fleksibel sesuai dengan kebutuhannya, dapat melindungi kaki, nyaman dan tentunya memiliki nilai estetika yang tinggi. ${ }^{16,19}$ Permasalahan muncul pada orang yang sedang menderita penyakit pada kakinya seperti kaki neuropati diabetik, sehingga diperlukan pemahaman mengenai jenis pelindung kaki yang cocok untuk kaki neuropati diabetik dan kerugian yang dapat muncul apabila menggunakan pelindung kaki yang sama seperti pada kaki sehat. ${ }^{16,19}$ Studi menunjukan bahwa komplikasi kaki diabetik, seperti perubahan bentuk struktur tulang, keterbatasan gerakan sendi, pembentukan kalus dan menurunnya asupan pembuluh arteri, dapat mengakibatkan peningkatan tekanan plantar. ${ }^{16,19}$ Tekanan plantar yang meningkat tinggi dan terjadi secara berulang dapat menciptakan stress pada kaki dan kaki menjadi lebih rentan terhadap terbentuknya ulkus. ${ }^{16,19}$

Terdapat penelitian mengenai pengaruh riwayat ulkus kaki sebelumnya dengan tekanan plantar saat berjalan pada grup neuropati diabetik dengan riwayat ulkus (DNU), grup neuropati diabetik tanpa riwayat ulkus kaki (DN) dan grup subjek control (CG) menggunakan alat pengukur tekanan plantar, yakni Predar- $X$ insole. $^{20}$ Penelitian ini menemukan bahwa puncak tekanan plantar tertinggi terjadi di daerah midfoot dengan nilai DNU $(290,7 \pm 151,5 \mathrm{kPa})$, DN $(205,3 \pm 118,6$ $\mathrm{kPa})$ dan CG $(139,4 \pm 76,4 \mathrm{kPa})$. Sedangkan pressure time integral (PTI) di daerah midfoot dan rearfoot juga meningkat dengan nilai DNU (midfoot $68,7 \pm 36,5 \mathrm{kPa}$ dan rearfoot $102,5 \pm 37,9 \mathrm{kPa}$ ), DN (midfoot 43,3 $\pm 9,1 \mathrm{kPa}$ dan rearfoot 94,9 $\pm 29,4 \mathrm{kPa}$ ), CG (midfoot $37,3 \pm 11,4 \mathrm{kPa}$ dan rearfoot $83,3 \pm 21,2 \mathrm{kPa}$ ). Hasil ini menunjukan bahwa riwayat ulkus kaki pada subjek neuropati diabetik mempengaruhi distribusi tekanan plantar, sehingga terjadi peningkatan tekanan plantar pada midfoot serta PTI pada midfoot dan rearfoot. ${ }^{20}$ Penelitian menemukan bahwa pada kaki yang mengalami neuropati diabetik menciptakan beban tekanan plantar kaki yang lebih tinggi dari pada orang normal, sehingga kaki menjadi lebih rentan dan memerlukan perlakuan yang khusus dari alat pelindung kaki yang akan digunakannya. ${ }^{20}$

Alat pelindung kaki yang digunakan oleh penderita kaki neuropati diabetik dapat dilakukan modifikas pada bagian-bagian tertentu sesuai fungsinya masing-masing, karena memiliki hubungan silang dalam memproteksi kaki penderita neuropati diabetik. ${ }^{4}$ Bila hubungan ini diacuhkan maka sepatu akan memberikan dampak yang merugikan kepada kaki. ${ }^{4}$ Secara teknis, terdapat beberapa kemungkinan untuk mempertahankan keharmonisan hubungan ini, termasuk adaptasi terhadap sepatu itu sendiri. ${ }^{4}$

Berikut adalah bagian dari sepatu yang dapat dimodifikasi, antara lain: ${ }^{4}$ 


\section{Insole}

Insole merupakan alas bagian dalam kaki yang mengadakan kontak dengan permukaan kaki. Penderita neuropati kaki diabetik memerlukan, custom-made insole (dibuat sendiri), karena berperan penting untuk mengurangi tekanan melalui prinsip "kontak penuh" (membungkus rapat kaki) dengan bahan peredam kejut. Modifikasi dapat dilakukan dengan memilih bahanbahan yang lembut.

2. Shoe height

Ketinggian dari alat pelindung kaki dapat digolongkan menjadi tiga tipe, yakni high, bottie (setinggi pergelangan kaki) dan low. Kemampuan untuk mentransfer daya tekanan pada kaki ditemukan pada tipe high (tinggi), sehingga dapat mengurangi tekanan dibagian tertentu pada kaki. Tipe bottie digunakan apabila kaki cenderung untuk bergeser kedepan di dalam sepatu. Pemilihan shoe height dapat disesuaikan dengan luasnya area kaki yang akan dilindungi. Perlindungan di bagian distal kaki, seperti jari-jari kaki, dapat dipilih tipe low, atau sebaliknya.

3. Outsole profile

Profile rocker bottom sole, yakni pelindung kaki dengan outer sole yang melengkung (tidak datar) dan berperan untuk pengaturan titik poros yang berbeda-beda di kaki. Apabila ditemukan keterbatasan gerakan pada forefoot dapat dipilih rocker bar, yaitu salah satu dari tipe rocker bottom sole, dengan bagian yang melengkung di area forefoot saja. Melalui tipe ini, titik poros dipindahkan dekat dengan metatarsophalanges (MTPs) sehingga tekanan plantar di area forefoot dapat dikurangi. Kondisi ini disebut sebagai titik poros dini. Profile rocker bottom memerlukan outsole yang kaku dan dibuat keras.

\section{Outsole flexibility}

Fleksibilitas outsole dapat dilakukan modifikasi, seperti dibuat kaku, diperkeras atau kenyal. Bentuk kaku diperlukan untuk mengurangi tekanan pada satu area tertentu pada kaki, bisa juga untuk memperbaiki bentuk kaki dan memfiksasi kaki di dalam sepatu. Bentuk kaku diperlukan apabila kaki melakukan gerakan yang terbatas saja. Bentuk kenyal tidak boleh lebih kenyal dari pada kontur kaki, karena dapat menimbulkan gesekan antara kaki dengan bagian dalam sepatu.

5. Leg

Leg memiliki berbagai macam tingkat fleksibilitas yang berhubungan dengan tingkat fleksibilitas outsole. Outsole yang kaku bila dikombinasikan dengan tipe leg yang berukuran tinggi dan kenyal akan mengakibatkan sepatu mengkerut dan menimbulkan gesekan pada kaki.

6. Tongue

Tingkat fleksibilitas tongue harus disamakan dengan fleksibilitas outsole dan leg. Tongue yang kenyal dan komplit cenderung tertarik kedalam sepatu.

7. Heel

Heel dapat dibuat dari bahan yang elastis agar dapat meningkatkan kemampuan shock absorbance. Pada kasus drop-foot tingkat menengah, heel dibuat membulat untuk mengkekang kaki yang jatuh.

Dahmen membuat alogaritma tentang pemilihan bentuk modifikasi pelindung kaki yang baik dan sesuai dengan kondisi kecacatan akibat neuropati pada kaki (Tabel $1)^{4}$

Pada praktek sehari-hari, pasien yang mengalami kecacatan pada kaki sering diberikan pelindung kaki yang khusus untuk mencegah terjadinya ulkus. ${ }^{21}$ Terutama pada pasien dengan neuropati diabetik yang mengalami penurunan sensasi sensoris pada kaki mereka. ${ }^{21}$ Bila meresepkan pelindung kaki yang tidak tepat dan stuktur kaki tidak diseimbangkan, maka jaringan lunak pada plantar kaki akan mengalami stress yang berlebihan dan dapat berkembang menjadi ulkus sebagai akibat dari akumulasi trauma. ${ }^{21}$ Pelindung kaki khusus yang dibuat oleh para pakar podiatri merupakan indikator keberhasilan terapi. ${ }^{21}$ Pelindung kaki khusus dapat memperbaiki area kontak pada kaki, puncak tekanan plantar secara lokal dan pressure time integral (PTI) sehingga dapat mencegah timbulnya ulkus. ${ }^{21}$ 
Tabel 1. Alogaritma Alat Pelindung Kaki Terapeutik untuk Penderita Kaki Neuropati ${ }^{4}$

\begin{tabular}{|c|c|c|c|c|c|c|c|c|}
\hline \multicolumn{9}{|c|}{ Shoe } \\
\hline & Medical feature & Insole & Height & $\begin{array}{l}\text { Pivot } \\
\text { point }\end{array}$ & Outsole & Leg & Tongue & Heel \\
\hline 1.1 & Sensory loss & No & Low & $N A$ & Supple & Supple & Supple & Normal \\
\hline 1.2 & $\begin{array}{l}\text { Sensory and } \\
\text { autonomic } \\
\text { dysfunction }\end{array}$ & Yes & Low & $N A$ & Supple & Supple & Supple & $\begin{array}{l}\text { Resilient } \\
\text { material }\end{array}$ \\
\hline 2 & $\begin{array}{l}\text { Limited joint } \\
\text { mobility }\end{array}$ & Yes & Low & Normal & Toughened & Supple & Supple & $\begin{array}{l}\text { Resilient } \\
\text { material }\end{array}$ \\
\hline 3.1 & $\begin{array}{l}\text { Hollow-foot } \\
\text { with claw toes }\end{array}$ & Yes & Bottine & Early & Toughened & Toughened & Toughened & $\begin{array}{l}\text { Resilient } \\
\text { material }\end{array}$ \\
\hline 3.2 .1 & $\begin{array}{l}\text { Flexible flatfoot } \\
\text { with hallux } \\
\text { valgus }\end{array}$ & Yes & High & Normal & Toughened & Toughened & Toughened & $\begin{array}{l}\text { Resilient } \\
\text { material }\end{array}$ \\
\hline 3.2 .2 & $\begin{array}{lr}\text { Rigid } & \text { flatfoot } \\
\text { with } & \text { hallux } \\
\text { valgus } & \end{array}$ & Yes & Bottine & Early & Toughened & $\begin{array}{l}\text { Strong } \\
\text { medial } \\
\text { support }\end{array}$ & Toughened & $\begin{array}{l}\text { Resilient } \\
\text { material }\end{array}$ \\
\hline 3.3 & Charcot foot & Yes & High & Early & Stiff & Stiff & Toughened & $\begin{array}{l}\text { Resilient } \\
\text { material }\end{array}$ \\
\hline 4.1 & $\begin{array}{l}\text { Hallux } \\
\text { amputation }\end{array}$ & Yes & High & Early & Stiff & Toughened & Toughened & $\begin{array}{l}\text { Resilient } \\
\text { material }\end{array}$ \\
\hline 4.2 & $\begin{array}{l}\text { Forefoot } \\
\text { amputated }\end{array}$ & Yes & High & Early & Stiff & Stiff & Stiff & $\begin{array}{l}\text { Resilient } \\
\text { material }\end{array}$ \\
\hline 5 & Ulceration & Yes & High & Early & Stiff & Stiff & Toughened & $\begin{array}{l}\text { Resilient } \\
\text { material }\end{array}$ \\
\hline
\end{tabular}

Modifikasi pada bagian outsole dari pelindung kaki telah membuktikan adanya perbaikan yang memuaskan pada penderita kaki neuropati diabetik. Terdapat penelitian pada tiga jenis disain sepatu yang telah dimodifikasi pada outsole nya dengan mengukur tekanan plantar pada region forefoot, midfoot dan hindfoot penderita yang mengalami diabetes jangka panjang serta memiliki resiko terjadinya ulkus. ${ }^{22}$ Penelitian yang menggunakan Insole foot Scan ini menemukan bahwa sepatu dengan tipe rocker bottom dapat mengurangi tekanan sebesar 35$65 \%$ pada tumit dan midfoot. ${ }^{22}$ Tipe ini juga merupakan cara yang paling efektif untuk mengurangi beban pada forefoot kaki penderita neuropati diabetik (Gambar 3). ${ }^{22}$
Hasil penelitian ini juga didukung oleh pengamatan tiga jenis outsole sepatu tipe rocker dan menemukan bahwa tekanan plantar pada area forefoot dapat diseimbangkan dengan menggeser tekanan ke midfoot seperti pada sepatu tipe negative-heel dan toe only rocker. ${ }^{23}$ Kedua penelitian ini menunjukan bahwa peranan outsole terutama tipe-tipe rocker-bottom memiliki peranan penting dalam menurunkan tekanan plantar. ${ }^{22,23}$

Modifikasi variasi insole antara permukaan kaki dengan bagian dalam outsole juga dapat meningkatkan luas kontak area pada plantar sehingga tekanan plantar dapat dikurangi. ${ }^{22}$ Peranan insole dalam menurunkan tekanan pada forefoot sangat bervariasi, berbeda dengan hasil yang didapat ada hindfoot. ${ }^{22}$ 


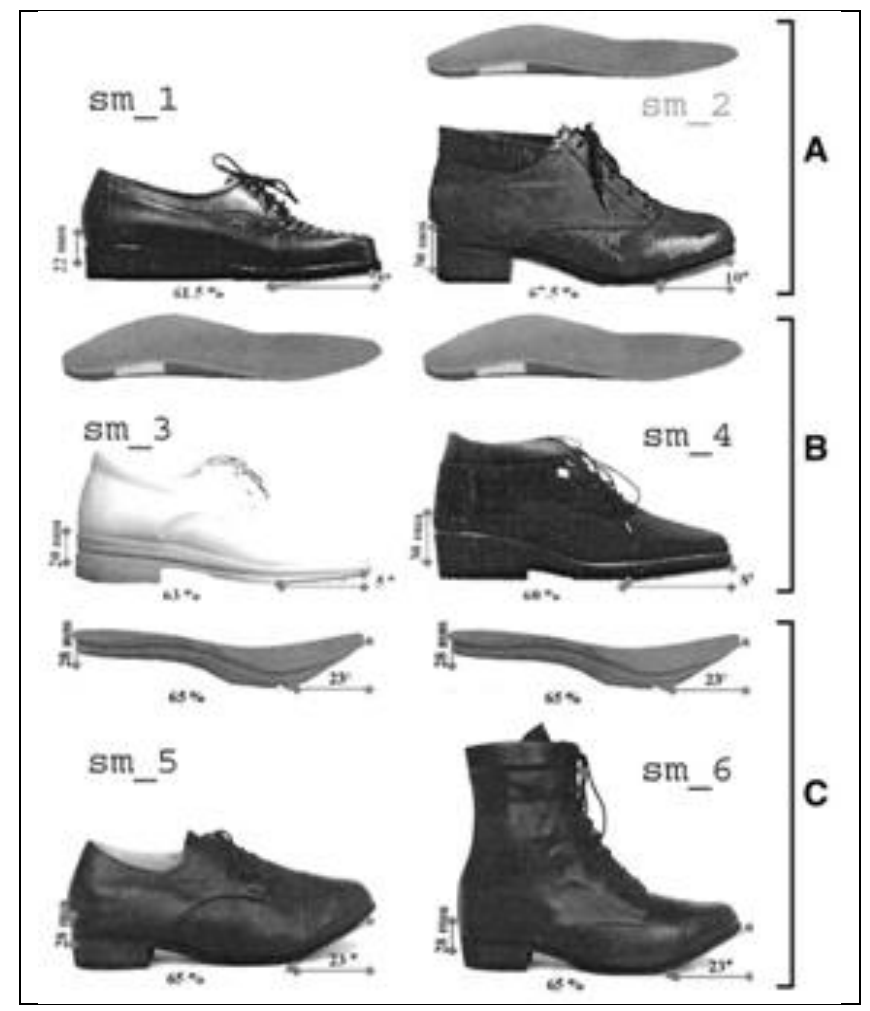

Gambar 3. Enam Bentuk Sepatu Terapeutik pada Penelitian Praet SFE, dkk (2003). Alas kaki yang digunakan ditunjukan pada bagian atas. Panah mengindikasikan posisi aksis rocking relative, rocking angle dan relative heel height ${ }^{22}$

Puncak tekanan di caput metatarsal (midfoot) pada variasi insole yang terbuat dari bahan microcellular rubber (MCR), polyurethane foam, ethylene vinyl acetate (EVA) dan insol pasien sendiri yang berbahan kain menemukan penurunan tekanan plantar pada ketiga grup pertama setelah sembilan bulan proses adaptasi (group 1: 6,9 $\pm 3,6,-57,4 \%$; grup 2: $6,2 \pm 3,9,-61,96 \%$; dan grup 3: $6,8 \pm 6,1 \mathrm{kPa}$, $58,02 \% ; P=0,0001)$, namun pada grup ke empat menunjukan peningkatan tekanan plantar (group 4: 40,7 $\pm 20,5 \mathrm{kPa},+39,38 \%$; $P=0,008)$. Grup ke empat juga menunjukkan presentasi yang tinggi terhadap kemunculan luka baru sebesar 33\%, bila dibandingkan dengan luka baru pada grup satu dan dua sebesar 4\%, serta luka baru pada grup ke tiga sebesar 3\%. Melalui data ini, diketahui bahwa kaki memerlukan waktu adaptasi terhadap pelindung kaki terapeutik agar dapat mencapai penurunan tekanan plantar yang optimal dan pelindung kaki non terapeutik tidak dapat menurunkan tekanan plantar secara signifikan sehingga ulkus kaki masih menjadi masalah utama dalam proses penyembuhan kaki. ${ }^{24}$

Puncak tekanan plantar pada region of Interest (ROI), yakni area-area pada telapak kaki pasien yang menjadi target optimasi penurunan tekanan plantar, pada penderita dengan riwayat ulkus kaki neuropati diabetik dan pasien yang memiliki salah satu kecacatan kaki, seperti claw atau hammer toes, hallux valgus, midfoot charcoat deformity, keterbatasan mobilitas sendi, pes planus atau pes cavus yang mendapat pelindung kaki khusus pernah diteliti berdasarkan cetakan dari kaki pasien langsung. ${ }^{25}$ Pengukuran dilakukan berdasarkan algoritma sebagai panduan nilai keberhasilan modifikasi alas kaki dan sepatu, yakni harus dibawah $200 \mathrm{kPa}$ pada ROI tertentu di kaki. ${ }^{25}$ Modifikasi yang dilakukan dapat berupa modifikasi bentuk alas kaki (insole), mengubah kelembutan materinya, mengubah penutup sepatu, penambahan bantalan pada area metatarsal, hallux atau bar metatarsal, hingga kepada mengubah tapal sepatu (outersole). ${ }^{25}$ Modifikasi juga dapat dilakukan lebih dari satu kali pada satu pelindung kaki. Penelitian ini mendapati adanya total 35 ROIs yang perlu dilakukan optimasi pelindung kaki, 17 ROI berlokasi pada caput metatarsal, 13 ROI pada hallux dan 5 ROI pada midfoot. ${ }^{25}$ Setelah dilakukan pengukuran paska modifikasi, ditemukan 
minimum $25 \%$ pemulihan tekanan pada 16 ROI bila dibandingkan dengan baseline, 7 ROI mengalami penurunan tekanan dibawah 200 $\mathrm{kPa}$ dan 12 ROI menunjukan kedua kriteria. ${ }^{25}$ Puncak tekanan secara signifikan berkurang 95 $\mathrm{kPa}(30,2 \%, \mathrm{P}<0,001)$ dengan mean puncak tekanan baseline sebesar 303 (SD 77) sehingga menjadi 208 (SD 46) paska modifikasi pelindung kaki. ${ }^{25}$ Sementara itu tidak ada perbedaan signifikan antara hasil mean pemulihan puncak tekanan yang diperoleh dari ke empat teknisi sepatu. ${ }^{25}$ Penelitian ini menunjukkan bahwa penderita kaki neuropati diabetik memiliki pola puncak tekanan plantar yang bervariasi pada ROI di kakinya. ${ }^{25}$ Variasi pola puncak tekanan plantar pada ROI dapat diturunkan dengan melakukan modifikasi pada bagian-bagian tertentu pada pelindung kaki, sehingga kita dapat membuat pelindung kaki terapeutik yang dapat memberikan efek yang optimal kepada kaki penderita. ${ }^{25}$

\section{Penutup}

Ulkus pada kaki disebabkan oleh banyak faktor, baik dari luar seperti trauma ataupun dari dalam tubuh pasien seperti penyakit diabetes melitus. Tingginya kadar gula dalam darah pada penderita diabetes melitus, dapat menimbulkan berbagai macam komplikasi mikrovaskuler dan neuropati, sehingga komplikasi yang paling sering terjadi adalah ulkus kaki diabetik. Penderita dengan ulkus kaki diabetik cenderung mengalami kerusakan jaringan progresif yang akan mengakibatkan amputasi hingga kematian, sehingga diperlukan terapi medikamentosa dan tindakan pencegahan. Tindakan pencegahan ini dapat berupa pemberian edukasi mengenai pola makan, perubahan gaya hidup hingga kepada penggunaan alat pelindung kaki yang tepat. Pada penderita ulkus kaki diabetik memerlukan perlakuan yang khusus terhadap kondisi kelemahan pada kakinya sehingga pelindung kaki biasa pada orang normal saja tidak cukup memproteksi kaki dari munculnya luka, bahkan dapat memperburuk luka tersebut sehingga mencetuskan ulkus ataupun luka yang baru. Hal ini disebabkan karena keadaan kaki diabetiknya telah membuat perubahan distribusi tekanan plantar, sehingga kaki akan menerima tekanan plantar lebih berat dari pada kondisi kaki normal.

Terdapat peningkatan puncak tekanan plantar yang signifikan pada kaki penderita diabetes bila dibandingkan dengan kaki normal, sehingga dengan diberikan pelindung kaki khusus yang sudah dimodifikasi dapat menurunkan puncak tekanan plantar. ${ }^{19}$ Modifikasi pada pelindung kaki harus dilakukan secara bertahap agar pasien dapat beradaptasi dengan pelindung kaki barunya dan disesuaikan dengan bentuk kaki yang berbeda-beda pada setiap pasien. Penderita kaki diabetik cenderung melakukan kesalahan dalam memilih ukuran sepatu dan hal ini dapat mengiduksi permulaan dari munculnya ulkus pada kaki diabetik, ${ }^{26}$ sehingga edukasi mengenai pemeliharan kebersihan kaki dan pengunaan pelindung kaki yang dibuat khusus (custom-made) pada penderita ulkus kaki diabetik, sangat penting untuk mendukung proses pemulihan penderita kaki diabetik.

Peranan obat-obat kedokteran masih merupakan pilihan utama dalam tindakan penyembuhkan ulkus kaki diabetik, namun efektifitasnya akan berkurang bahkan dapat menimbulkan resistensi obat apabila tidak didukung dengan tindakan pencegahan faktorfaktor yang dapat memperburuk penyembuhan ulkus kaki diabetik. Hal inilah yang menyebabkan ilmu pedotrik terus berkembang dan menjadi popular pada kalangan peneliti.

\section{Daftar Pustaka}

1. Long JT, Klein JP, Sirota NM, Wertsch JJ, Janisse D, Harris GF. Biomechanics of the double rocker sole shoe: Gait kinematics and kinetics. Conf Proc Annu Int Conf IEEE Eng Med Biol Soc IEEE Eng Med Biol Soc Conf. 2004;7:510710.

2. Diabetes: facts and figures [Internet]. International diabetes federation. Diunduh dari: http://www.idf.org /worlddiabetesday/toolkit/gp/facts-

figures. Pada 9 Okt 2014

3. Rovan U, Vilma. Causes of diabetic foot lesions. The Lancet. 2005;366(9498): 1675.

4. Dahmen R, Haspels R, Koomen B, Hoeksma AF. Therapeutic footwear for the neuropathic foot: An algorithm. Diabetes Care. 2000;24(4):705-9.

5. Hamilton N, Weimar W, Luttgens $\mathrm{K}$. Kinesiology: Scientific basis of human motion. 11th ed. Boston: McGraw-Hill; 2008; 193-5 p. 
6. Riegger CL. Anatomy of the ankle and foot. Phys Ther. 1988;68(12):1802-14.

7. Standring S. Gray's anatomy: The anatomical basis of clinical practice. 13th ed. Philadelphia, USA: Elsevier churchill livingstone; 2008; h.115

8. Lippert LS. Clinical kinesiology and anatomy. 5th ed. Philadelphia: F.A. Davis Company; 2011; h.332

9. Foot [image on the internet]. Kidport.com. c2012. Diunduh dari: http://kidport.com/reflib/ science/humanbody/skeletalsystem/Foot. htm. Pada 19 Oktober 2014

10. Putz R, Pabst R. Sobotta : Atlas anatomi manusia. 21st ed. Jakarta: EGC; 2000. h.346-7

11. Hamill J, M. Knutzen K. Biomechanical : basic of human movement. 2nd ed. Philadelphia, USA: Lippincott Williams \& Wilkins; 2003; h.212-3

12. Departemen. buku ajar ilmu penyakit dalam. 4th ed. Jakarta: Fakultas Kedokteran Indonesia; 2006; h.1924-33

13. Departement. ilmu penyakit kulit dan kelamin. 3rd ed. Jakarta: Fakultas Kedokteran Indonesia; 1999; h.36-227

14. J. McPhee S, F. Ganong W. Patofisiologi penyakit: Pengantar menuju kedokteran klinis. 5th ed. Jakarta: EGC; 2009.

15. Clayton W, Elasy TA. A Review of the pathophysiology, classification, and treatment of foot flcers in diabetic patients. Clin Diabetes. 2009;27(2):52-8.

16. Risk factors for diabetic foot ulcers: The first step in prevention [Internet]. Diunduh dari: http://www.consultant 360.com/articles/risk-factors-diabeticfoot-ulcers-first-step-prevention. 7 Okt 2014

17. Footwear function [Internet]. TheFreeDictionary.com. Diunduh dari :: http://medical-dictionary.thefreedicti onary.com/footwear+function. 8 Okt 2014
18. European Commission. European classification of goods: Classifying footwear [Internet]. 2013. Diunduh dari: http://rade.ec.europa.eu/doclib/docs /2013/may/tradoc_151161.pdf. 8 Okt 2014

19. Tsung BYS, Zhang M, Mak AFT, Wong MWN. Effectiveness of insoles on plantar pressure redistribution. J Rehabil Res Dev. 2004;41(6A):767-74.

20. Bacarin TA, Sacco ICN, Hennig EM. Plantar pressure distribution patterns during gait in diabetic neuropathy patients with a history of foot ulcers. Clin São Paulo Braz. 2009;64(2):113-20.

21. Castro E. Pedorthic Management of the Neuropathic Foot. Journal of Prosthetics and Orthotics. 17th ed. arizona; 2005;324.

22. Praet SFE, Louwerens J-WK. The influence of shoe design on plantar pressures in neuropathic feet. Diabetes Care. 2003;26(2):441-5.

23. Brown D, Wertsch JJ, Harris GF, Klein J, Janisse D. Effect of rocker soles on plantar pressures. Arch Phys Med Rehabil. 2004;5(1):81-6.

24. Viswanathan V, Madhavan S, Gnanasundaram S, Gopalakrishna G, Das BN, Rajasekar S, et al. Effectiveness of different types of footwear insoles for the diabetic neuropathic foot: a follow-up study. Diabetes Care. 2004;27(2):474-7.

25. Bus SA, Haspels R, Busch-Westbroek TE. Evaluation and optimization of therapeutic footwear for neuropathic diabetic foot patients using in-shoe plantar pressure analysis. Diabetes Care. 2011;34(7):1595-600.

26. Meyr AJ, Creech C,.Perceptions of appropriate shoe size in diabetic patients presenting for initial podiatric evaluation. Journal of Diabetic Foot Complications. 2011;3(2): 40-2 